\title{
Research on Quantitative Evaluation Model of Investment Value of Power Grid Enterprises' New Business Based on Real Options
}

\author{
Wang Yongli ${ }^{1}, \mathrm{Xu} \mathrm{Nan}{ }^{2}$, Wang Xiaohui ${ }^{3}$, Zhou Minhan ${ }^{1, *}$, Wang $\mathrm{Lei}^{4}$ \\ ${ }^{1}$ School of Economics and Management, North China Electric Power University. Beijing, China \\ ${ }^{2}$ Economic and Technical Research Institute of State Grid Hebei Electric Power Co., Ltd. Hebei, China \\ ${ }^{3}$ State Grid Economic Technological Research Institute Co., Ltd. Beijing, China \\ ${ }^{4}$ Institute of Industrial Economics, Chinese Academy of Social Sciences. Beijing, China
}

\begin{abstract}
With the continuous advancement of the power system reform, especially after the introduction of equipment capital to participate in the competition, the business development of power grid companies is facing increasingly severe internal and external tests. While continuing to do a good job in regulated businesses centered on transmission and distribution business, vigorously develop new businesses and strive to achieve high-quality development in a complex market environment. Through the evaluation of the intrinsic value of new businesses of power grid companies, investors can clarify the true value of new businesses, better identify and avoid potential risks, and encourage investors to invest rationally. This article first expounds the types of new businesses of power grid companies, introduces the basic overview of real option theory, and constructs a value evaluation model of discounted cash flow model plus real option theory pricing model, and through case analysis, the feasibility of empirical option theory in the evaluation of new business of power grid investment value is verified.
\end{abstract}

\section{Introduction}

At present, the most important core business of power grid companies is to build a safe, reliable, green, and efficient smart grid [1], to provide high-quality power supply services to customers in the region, and to meet the demand for electricity for economic and social development. In the new era, especially in the context of the rapid development of smart grids, the operation mode and overall structure of grid companies need to be adjusted accordingly, vigorously develop new businesses, and strive to achieve high-quality development in a complex market environment.

Through the evaluation of the intrinsic value of new businesses of power grid companies, investors can clarify the true value of new businesses, better identify and avoid potential risks, and encourage investors to invest rationally. At the same time, observing power grid companies from a dynamic perspective, not only focuses on the value of existing assets in the company, but also explores the potential value within the company [2]. This can enable investors to more accurately understand the development potential of the new business of power grid companies, determine whether it has investment value, and whether to invest.

Power grid companies will have different strategic choices in the layout of new business development according to their own development positioning, but they generally rely on "Internet + " to develop e-commerce, integrated energy services, information communications, high-end equipment manufacturing and other new businesses [3].

\section{Real option theory}

An option is a right without related symmetrical obligations, that is, the option to buy or sell an agreed asset (stock) at a predetermined price on or before the expiry date. The concept of real option is similar to that of a financial option. When there is strong uncertainty in the future development of the company, enterprise managers pay a certain price in advance to obtain the option of flexible management of project investment plans or enterprise assets according to changes in the future market environment, and the managers can exercise this right when they are expected to obtain economic benefits. From the perspective of real options, the uncertainty of future development means an opportunity for companies to adjust their decisions at any time according to the uncertainty and turn the uncertainty into benefits.

According to the different investment projects or stages of the enterprise, managers can expand, contract, delay, abandon or change the project in any period of the project. Therefore, real options can be divided into

* Corresponding author: 15023620691@163.com 
growth options, contraction options, delay options, and conversion options. Recognizing the attributes of real options can help improve the accuracy of option value evaluation. Real options are the application of financial option pricing principles in the field of real asset pricing. Therefore, the pricing models of real options are derived from financial option pricing models, including BlackScholes (B-S) option pricing models and binary tree option pricing models. The nature of options is very important to choose an option pricing model reasonably [4].

\section{Investment value evaluation model based on real options}

\subsection{The applicability of real options in the investment value analysis of new businesses of power grid companies}

The evaluation of the investment value of the new business of the power grid company includes two aspects. The first is the income brought by its existing assets, and the second is the value created by the profitable potential projects. If the discounted free cash flow method is used to evaluate the overall value of new businesses, the potential value of new businesses is ignored. Therefore, this paper uses the real option pricing model to quantitatively evaluate the potential value of the new business of power grid companies.

First, both intangible assets and fixed assets have option characteristics. The core competitiveness of the new business of power grid companies is the research and development of knowledge-based and technological intangible assets, as well as applied fixed assets. The initial investment in technology research and development is large, the cycle is long, and the value cannot be seen immediately. It often reflects the characteristics of high investment, coupled with technological innovation, market demand changes, and high uncertainty in the future report of investment projects. From the perspective of real options, high uncertainty will increase the real option value of new businesses of power grid companies.

Second, project management and strategic flexibility have option value [5]. The value composition of the new business of power grid companies is mainly intangible assets and some fixed assets. Therefore, the flexibility of investment decisions for new businesses is relatively high. The investment can be expanded, reduced or abandoned according to the progress of the project. From the perspective of real option theory, this management and strategy has the flexibility of option value.

\subsection{Construction of a quantitative evaluation model for the investment value of new businesses of power grid companies.}

By analyzing the applicability of existing project value evaluation methods, this article selects the free cash flow model in the income method to evaluate the value of existing assets. For the part of the potential value ignored by the income method, real option theory is used to construct an option pricing model. Because the B-S model does not need to predict the future increase and decrease of options, the model is simple and requires few parameters. The required data is relatively easy to obtain and can be improved. The objectivity of the calculation results. This paper uses this model to quantitatively evaluate the potential value of the new business of the power grid company, and constructs the overall value evaluation model of the new business of the power grid company with the free cash flow model and the BS option pricing model.

1. Valuation of the project's existing assets based on the free cash flow model

The discounted free cash flow model uses historical operating data of the project to predict its future free cash flow, and discounts the future free cash flow with an appropriate discount rate to obtain the value of the project's existing assets. The new businesses of power grid companies are growing rapidly in the growth stage, and the growth rate changes every year. As the project develops, it will gradually enter a stable growth period, and the growth rate of the project will stabilize. Therefore, this paper chooses a two-stage model that meets the characteristics of the new business development of power grid companies. The specific model is as follows:

$$
V_{1}=\sum_{t=1}^{n} \frac{F C F F_{1}}{(1+\mathrm{WACC})^{\mathrm{t}}}+\frac{F C F F_{n}+1}{(1+\mathrm{WACC})^{\mathrm{n}} \times(\mathrm{WACC}-\mathrm{g})}
$$

In the formula, ${ }^{{ }_{1}}$ is the current asset value of the project, $F C F F_{t}$ is the project's free cash flow in the first year of the forecast period, $W A C C$ is the weighted average cost of capital, and $g$ is the growth rate during the stable period.

2. Potential value evaluation based on B-S option pricing model

The Black-Scholes option pricing model (B-S model) follows the risk-neutral theory. All investors are riskneutral, and investors expect a risk-free rate of return [6]. The call option value in the B-S model can be expressed as the following model:

$$
\left\{\begin{array}{l}
V_{2}=S N\left(d_{1}\right)-K e^{-r t} N\left(d_{2}\right) \\
d_{1}=\frac{\ln \frac{S}{K}+\left(r+\frac{\sigma^{2}}{2}\right) t}{\sigma \sqrt{t}} \\
d_{2}=d_{1}-\sigma \sqrt{t}
\end{array}\right.
$$

In the formula, $S$ is the current value of the underlying asset, $K$ is the exercise price of the option, $t$ is the validity period of the option, $r$ is the risk-free interest rate corresponding to the option period, and $\sigma$ is the volatility rate of the value of the underlying asset.

\section{Example analysis}


Take the G Grid Company as an example. According to the G Grid Company's annual financial statement disclosure, G Company plans to add an integrated energy service to its business. Decision makers of G Company can invest in the project or give up based on the current feedback from the integrated energy business market. The decision of the project, therefore, can be foreseen that G Grid Company has an expansion option.

\subsection{Valuation of $\mathbf{G}$ company's existing assets}

This paper uses the discounted free cash flow model in the discounted cash flow method to evaluate the value of company G's existing assets. The time range of the company's future free cash flow forecast includes the detailed forecast period and subsequent period. The detailed forecast period generally predicts the free cash flow of the company in the next 5-7 years, this article selects 2020-2024 as the detailed forecast period, and the beginning of 2025 as the follow-up period of stable development. According to the theory of competitive equilibrium, the sales growth rate of a company in a stable state of operation can be approximately equal to the nominal growth rate of the macro economy. Excluding the effect of inflation, the macroeconomic growth rate is roughly between $2 \%$ and $6 \%$. Based on the current macroeconomic situation and related data, this article determines that the growth rate during the stable period is. The two-stage discounted free cash flow model is used to evaluate the value of G Grid Company existing assets. The evaluation base date is January 1, 2020. The formula for calculating free cash flow is as follows:

$$
F C F F=N I+I \times(1-T a x)+D E-C A-O C
$$

$$
F C F F=O N I_{T a x}+D E-C A-O C
$$

In the formula, $F C F F$ is corporate free cash flow, $N I$ is net profit, $I$ is interest expense, Tax is income tax rate, $D E$ is depreciation and amortization, $C A$ is capital expenditure, $O C$ is increase in working capital, and $O N I_{T a x}$ is net operating profit after tax.

Based on corporate audit reports and other relevant data, forecast the revenue, costs, expenses and other items of G Grid Company from 2020 to 2024 year by year, and calculate free cash flow through the above formula. The forecast results are as follows:

Table 1 Free cash flow of G Grid Company in the forecast

\begin{tabular}{|c|c|c|c|c|c|}
\multicolumn{7}{|c|}{ period Unit: ten thousand yuan } \\
\hline Years & 2020 & 2022 & 2023 & 2024 & 2024 \\
\hline $\begin{array}{c}\text { Free } \\
\text { cash } \\
\text { flow }\end{array}$ & 6830.84 & 7304.29 & 9027.93 & 10384.82 & 11983.67 \\
\hline
\end{tabular}

The discount rate in the free cash flow discount model should use the weighted average cost of capital. Select the 5-year treasury bond yield to maturity under the assessment base date January 1, 2020 as the risk-free yield, namely $r=4.27 \%$. The discount rate calculated by the weighted average cost of capital model is $16.32 \%$.

From this table, we can see the current value of $\mathrm{G}$ Grid Company $V_{1}$ is:

$$
\begin{aligned}
& V_{1}=\frac{6830.84}{(1+16.32 \%)}+\frac{7304.29}{(1+16.32 \%)^{2}}+\frac{9027.93}{(1+16.32 \%)^{3}}+\frac{10384.82}{(1+16.32 \%)^{4}} \\
& +\frac{11983.67}{(1+16.32 \%)^{5}}=28307.24
\end{aligned}
$$

\subsection{Quantitative assessment of G company potential value}

According to the B-S model, the estimated parameters that need to be determined include the current value of the underlying asset $S$, the exercise price of the option $K$, the effective period of the option $t$, the riskfree interest rate $r$ corresponding to the option period, and the volatility rate of the value of the underlying asset $\sigma$.

(1) The value of the underlying asset is the present value of the cash flow of the project. According to the future cash flow data of similar projects in the same industry, the value of the underlying asset is calculated as $S=29793.81$ yuan;

(2) The volatility of the underlying asset refers to the standard deviation of the volatility of future returns of the project. In this paper, the stock price volatility is used instead of the volatility of the project value, the maximum likelihood estimation method is used to solve the volatility in a fixed interval, and the annual volatility $\sigma=83.97 \%$ of the project is calculated;

(3) This calculation determines the exercise price of the option through the investment amount of the project. According to the relevant data of the enterprise, the projected investment cost of the project is $K=8936.05$ million yuan;

(4) The expiration time of the option is $t=3$ year for the construction period of the project.

(5) The risk-free rate of return selects the 5-year treasury bond yield to maturity on the base date of evaluation $r=4.27 \%$;

Bring the estimation results of the above parameters into the B-S model to get:

$$
\begin{aligned}
& d_{1}=\frac{\ln \frac{29793.81}{8936.05}+\left(4.27 \%+\frac{83.97 \%^{2}}{2}\right) \times 3}{83.97 \% \sqrt{3}}=1.5845 \\
& d_{2}=d_{1}-\sigma \sqrt{t}=1.5845-83.97 \% \times \sqrt{3}=0.1301
\end{aligned}
$$

By querying the cumulative probability distribution function table under the standard normal distribution:

$$
N\left(d_{1}\right)=0.9574, N\left(d_{2}\right)=0.7208
$$

Therefore, the real option value of company $\mathrm{G}$ can be calculated as:

$$
\begin{aligned}
& V_{2}=29793.81 \times 0.9574- \\
& 8936.05 e^{-4.27 \% \times 3} \times 0.7208=22379.23
\end{aligned}
$$

Company G's overall corporate asset value on January 1, 2020, on the assessment base date, is the current corporate value of $28,307.24+$ option value of $22,379.23=506,864,700$ yuan. 
In summary, running real option theory analysis and B-S option pricing model estimation, the overall asset value of G company has increased by $223,792,300$ yuan. The use of traditional enterprise value evaluation methods does not consider the potential value of the enterprise and underestimates the overall asset value of the enterprise.

\section{Conclusion}

This paper introduced the real option theory in the quantitative evaluation of the investment value of the new business of the power grid company, considering the characteristics of the new business of the power grid company and the valuation difficulties, constructs the value evaluation model of the discounted cash flow model and the real option theory pricing model, and passes the case analyzed and verify the feasibility of real option theory in the evaluation of the investment value of power grid new business. The disadvantage of this article is that it does not consider the compound option and option game situation in power grid companies, and the method of determining the volatility of the underlying asset will affect the value quantification result to a certain extent. At the same time, the options hidden by different companies are quite different and must be analyzed in combination with specific conditions when applying them.

\section{Acknowledgment}

The authors would like to thank the support of the State Grid Corporation Science and Technology Project: Research on Investment Value Evaluation and Investment Optimization Technology of Emerging Grid Business (1300-202056133A-0-0-00).

\section{References}

[1] Wu An'an. (2019) Development prospects and challenges of new business of power grid enterprises $[\mathrm{J}]$. Modern Economic Information, 18: 67-68.

[2] Zhang Ying. (2012) New business brings new elements to the brand development of power grid companies[J]. Power Electronics, 11(02): 10-13+23.

[3] Wang Xinyong, Wang Dong. Energy + Blockchain: Empowering New Business Prospects for Development [N]. State Grid News, 2019-0507(008).

[4] Xing Xiaoqiang, Tong Yunhuan. (2009) An Empirical Study of New Technology Investment Decision Based on Real Options[J]. Chinese Management Science, 17(04): 30-38.

[5] Hao Weiya, Wei Wei, Wen Jun. (2016) How Does the Uncertainty of Economic Policy Affect Enterprise Innovation?- The Perspective of the Mechanism of Real Option Theory[J]. Economic Management, 38(10): 40-54.

[6] Zheng Zheng, Zhu Wuxiang. (2017) Research on the valuation of start-ups using the compound real option method[J]. Investment Research, 36(04): 118-135. 